\title{
Investigation of the wind generator blades material resistance to the lightning current action
}

\author{
Yuri Adamyan ${ }^{1}$, Sergey Krivosheev ${ }^{1}$, and Tatyana Minevich ${ }^{1, *}$ \\ ${ }^{1}$ Peter the Great Saint-Petersburg Polytechnic University, Polytechnicheskaya 29, 195251, Russian \\ Federation
}

\begin{abstract}
This paper is devoted to the problems of lightning protection of composite materials of wind generator blades. The results of experimental studies for carbon fibers under different types of lightning current pulse effects are provided. A significant increase in the degree of destruction of materials is shown for the pulse approximating field experiment results as compared with the standard lightning current pulse. We show that under the impact of the standard current pulse there is no significant material destruction, and the release of the discharge products is also insignificant. Also we shown that under the impact of the current pulse having a long «tail» time period (the current pulse close to the real one) there is an ignition of the carbon fiber composite material near the edges of the feeding electrode. With this the burning process doesn't end after the end of the current pulse. The description of the pulse current generator created for experiments is given.
\end{abstract}

\section{Introduction}

Intensive introduction of composite materials into all spheres of industry including renewable energy is reasonably caused by combining multiple functional characteristics, such as strength, elasticity, external impact persistence, low density, possibility of obtaining products of complex shapes. Application of composite materials in wind energy makes it possible both to increase the power of the wind power plants and to reduce the mass of the machinery and equipment. However, the resistance of the composite materials to lightning strikes has not been sufficiently studied by the present moment [1-6].

The statistical analysis of emergency situations, occurring when the lightning impacts the wind generator blades $[7,8]$, shows that the main damaging factor is not only the high amplitude of the lightning current pulse, but also the long-term impact of supporting current. The direct effect of the lightning current pulse can significantly worsen the mechanical properties of wind generator blades composite materials. The functional characteristics of the wind generator blades can be changed as well as the material of the

*Corresponding author: tm_21@ rambler.ru 
wind generator blades can ignite. These features of the composite materials should be considered in designing new wind power plants or during the analysis of the service properties of the existing plants.

\section{Materials and Methods}

Traditionally the standard lightning current pulse is applied for evaluating the impact of lightning current on the insulation properties while analyzing lightning protection of electric equipment [9-14]. Such a pulse is used for a wide range of problems associated [15-19] with a drastic increase of the current of the high amplitude (10-100 kA) and rise time about $1 \mu \mathrm{s}$. But this pulse doesn't simulate the whole complex of the lightning impact because of the lack of its energy. In particular, warming up the place of the lightning strike is not simulated. Such a pulse doesn't damage the composite material. The experiments on the Santis transmitter (Switzerland) showed that the actual forms of lightning currents were much different from the standard lightning current pulses [20].

For the analysis of the direct effect of the lightning processes on the structures of the power plant, it is necessary not to neglect the long-term impact of the supporting current which is an attribute of the lightning strike as an electric discharge [21]. The amplitude of the supporting lightning current is relatively low (about $1 \mathrm{kA}$ ) but the duration can reach $100 \mathrm{~ms}$. This current carries the main electric charge and causes a thermal breakdown of the composite material. Therefore, it is not advisable to apply the standard lightning current pulse for predicting the behavior of the composite material of the wind generator blades after the lightning strike.

For the experimental investigations of the composite material characteristics it is necessary to build the current generator which produces the current pulses of the actual form of the lightning current pulse. Such investigations were carried out in St. Petersburg Polytechnic University (SPbPU) under the Special Federal Program «Research and development on priority areas of Russian scientific and technological complex for 20142020» in collaboration with the foreign partner: Swiss Federal Institute of Technology in Lausanne (EPFL).

The investigation of the behavior of the composite material samples under the pulse impacts was carried out on the test complex containing the two-stage generator. This pulse current generator was able to provide an electric breakdown of the sample and to form the discharge channel. The composite material sample (with characteristic dimensions of $0.08 \times 0.08 \mathrm{~m}$ ) was placed on the metal base. The layer of the insulating material having dimensions smaller than the sample dimensions for providing electric contact around the edges was placed under the sample. For simulating the lightning current pulse effect by transferring the current pulse from the two-stage generator the steel electrode was located in the center of the sample.

The application of the two-stage generator in investigations was related to the necessity of modeling in the experiment two types of lightning current pulse impact: «fast» (the flow of discharge current 20-40 kA during near 50 $\mu \mathrm{s}$ ) and «slow» (the flow of current having an amplitude about several $\mathrm{kA}$ during near $1 \mathrm{~ms}$ ). For the accurate simulating of the real lightning time period structure there were two stages in the pulse generator: «fast» and «slow» correspondingly.

The «fast» stage of the generator is a pulsed current source capable of producing the exponentially decaying current pulse having amplitude of 10-40 kA and half-width duration of $20-100 \mu \mathrm{s}$ in the sample having electric resistance of several hundred Ohm. The «slow» stage of the generator is switched on when the current of the «fast» stage drops to the value 
of 1-2 kA, and then the current in the sample is hold on this level with a time constant of 1 $10 \mathrm{~ms}$.

For implementing the two-stage generator the matching unit was developed, the unit allows to jump from feeding «fast» stage to «slow» stage. The main problem is a significant difference in operating voltages of the stages that makes it problematic to apply the standard high-voltage switching elements.

The designed circuit diagram of the two-staged generator considered is shown in Fig. 1. The «fast» stage generator circuit $(\mathrm{C} 2)$ is made of high-voltage pulse capacitors with a busbar made of copper sheet. Output energy flows to the load via two parallel-connected sections of a high-voltage coaxial cable. Switching the «fast» stage is made with pseudospark discharger SW2. The exploded conductor is mounted in series with C2 (not shown in Fig.).

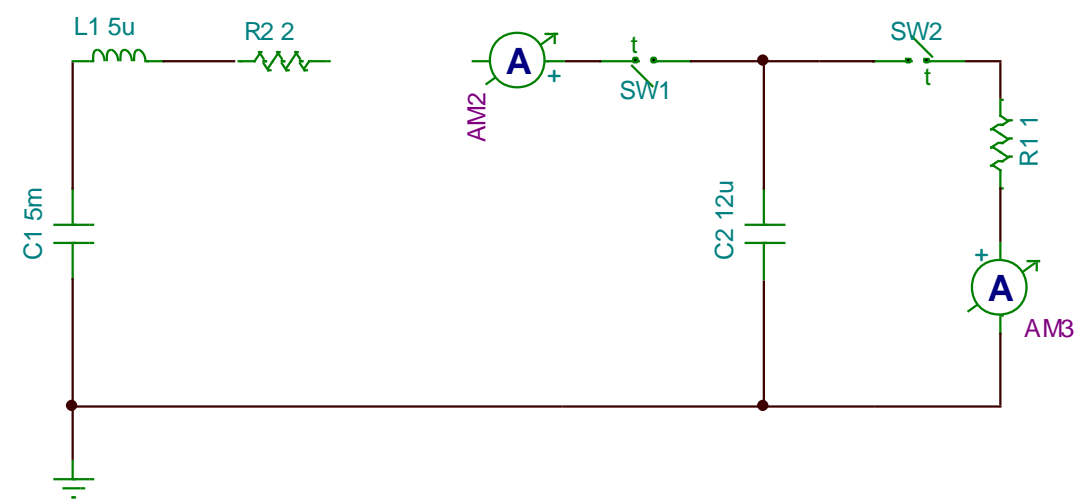

Fig. 1. The designed circuit diagram of the two-staged generator

The exploded conductor is structurally implemented by placing it between layers of sheet insulation of a solid state discharger. The «slow» stage (C1) is implemented by applying the capacitor bank having an operating voltage of $5 \mathrm{kV}$ and the whole capacity of $5.8 \mathrm{mF}$. The capacitor bank is mounted in the single unit with the charging device and the control system.

Before operating the generator it is necessary to separately charge the «fast» and the «slow» stages. The current pulses generation is initiated by the activation of the discharger SW2. The capacitor bank of the «fast» stage C2 begins to discharge which causes the explosion of the conductor. The explosion results in the insulation mechanical breakdown and activation of the discharger SW1.

\section{Results}

Fig. 2 shows the calculated oscillograms of the currents in the load and the «slow» stage. 


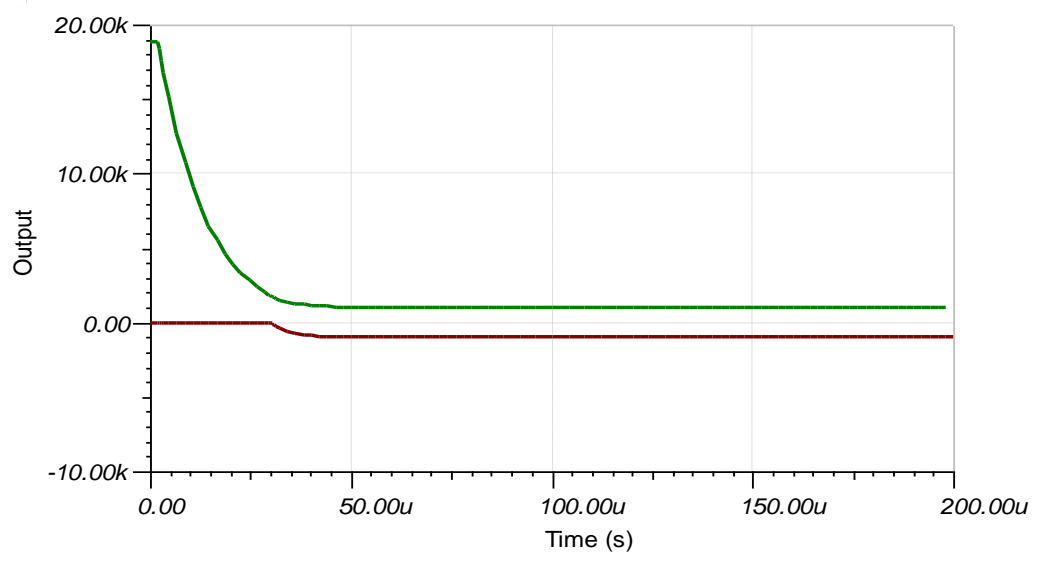

Fig. 2. The oscillograms of the currents in the load (top curve) and in the «slow» stage (lower curve)

For registering the form of the current pulse in the load the test complex is equipped with the specially designed Rogowski coil on the detachable ferrite core and with the highspeed camera Evercam 1000-4-M.

Fig. 3 shows the oscillogram of the current pulse created by only «fast» stage of the generator according to standardized form of the lightning current pulse.

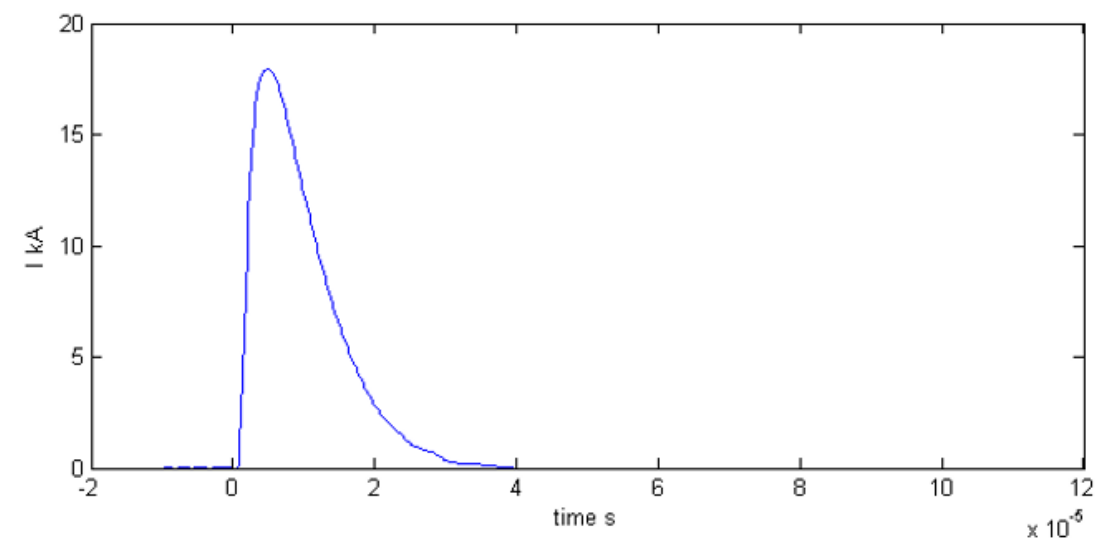

Fig. 3. The oscillogram of the current pulse according to standardized form of the lightning pulse

Fig. 4 shows photo of the sample before, and Fig. 5 shows photo of the sample after the impact of the current pulse created by only «fast» stage of the generator according to standardized waveform of the lightning pulse. 


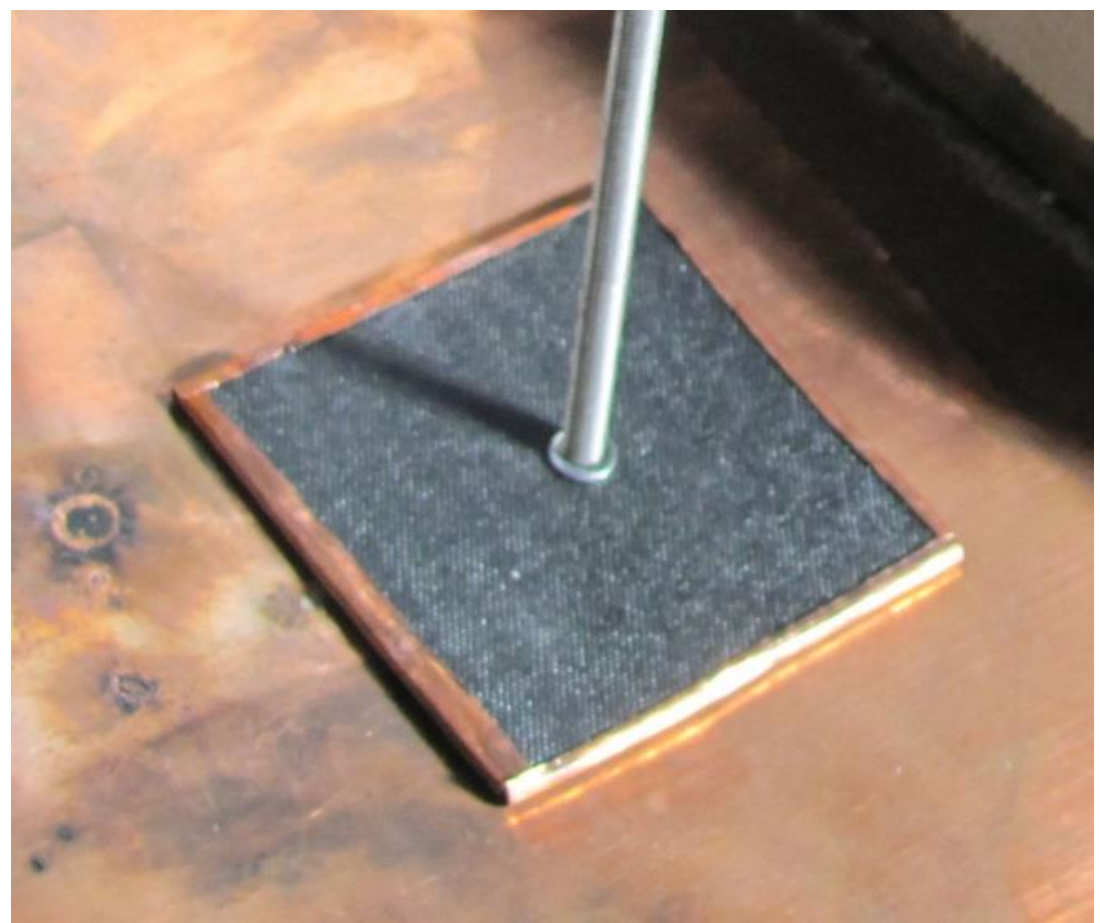

Fig. 4. Photo of the sample before the discharge

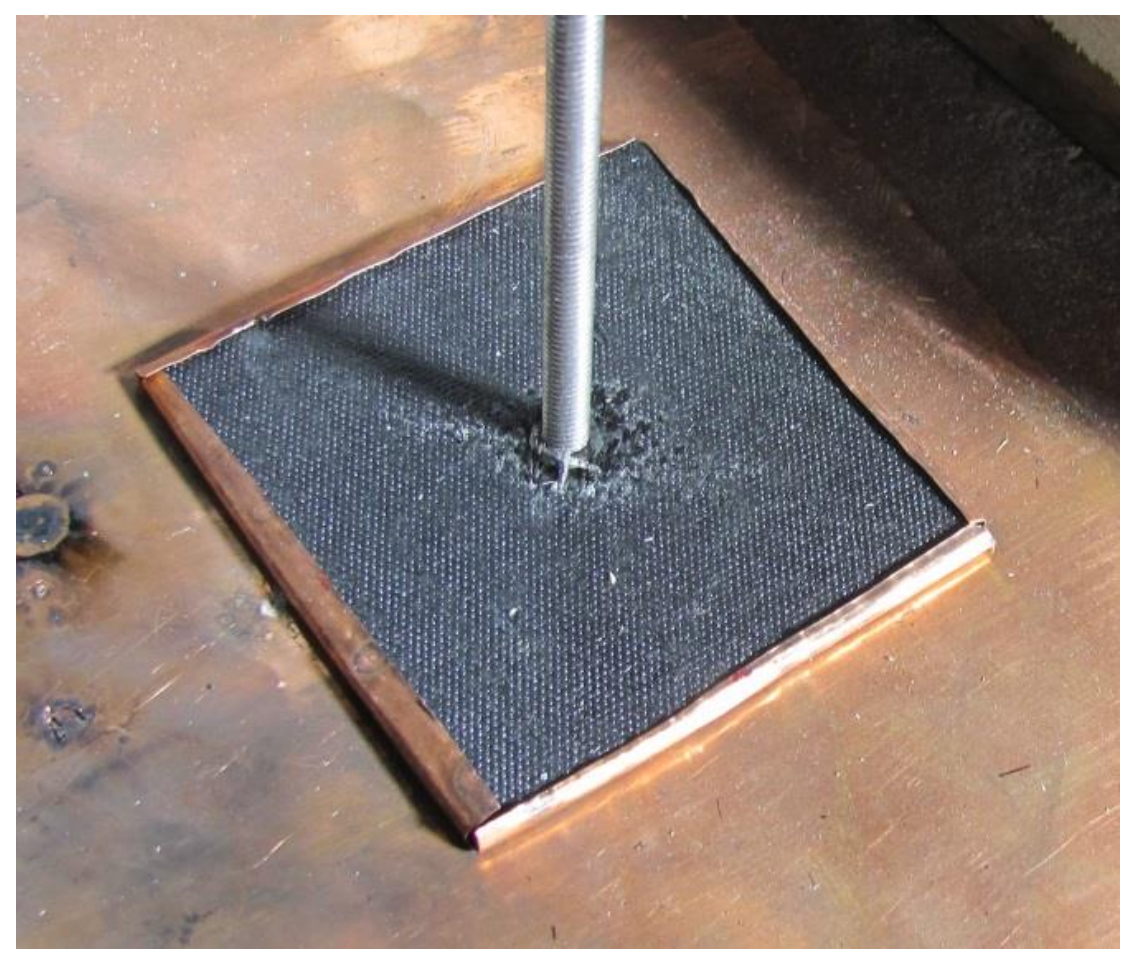

Fig. 5. Photo of the sample after the discharge 
A series of experiments made with the samples of the composite materials in the «fast» stage mode showed the breakdown along the fibers and the absence of the reach-through breakdown (Fig. 6).

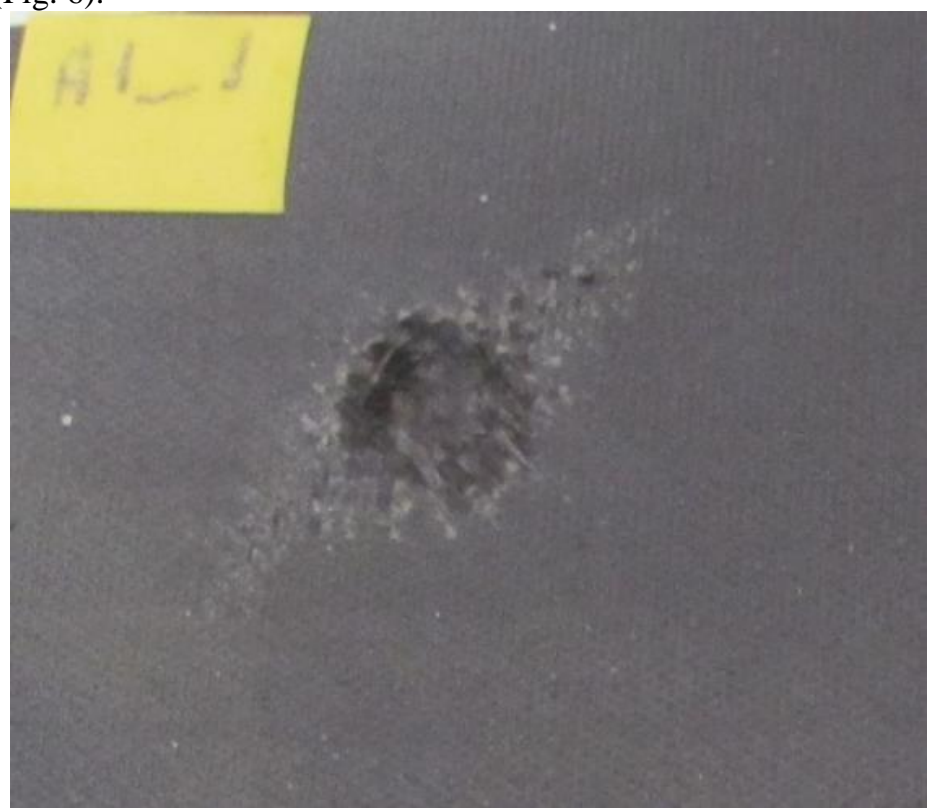

Fig. 6. Photos of the damage of the sample having been tested in the «fast» stage mode

Fig. 7 shows the oscillogram of the current pulse created by the «fast» stage and the «slow» stage of the pulse generator according to the real (experimentally obtained) waveform of the lightning current pulse. In the mode of the combined action of the «fast» stage and the «slow» stage of the generator after decaying «fast» current pulse there is a long phase of the release of the current about $1 \mathrm{kA}$, duration of which is characterized by the time constant of $10 \mathrm{~ms}$. The photos of the typical damage of the sample having been tested by the current pulse created by the «fast» stage and the «slow» stage of generator according to the real (experimentally obtained) waveform of the lightning current pulse are shown in Fig. 8.

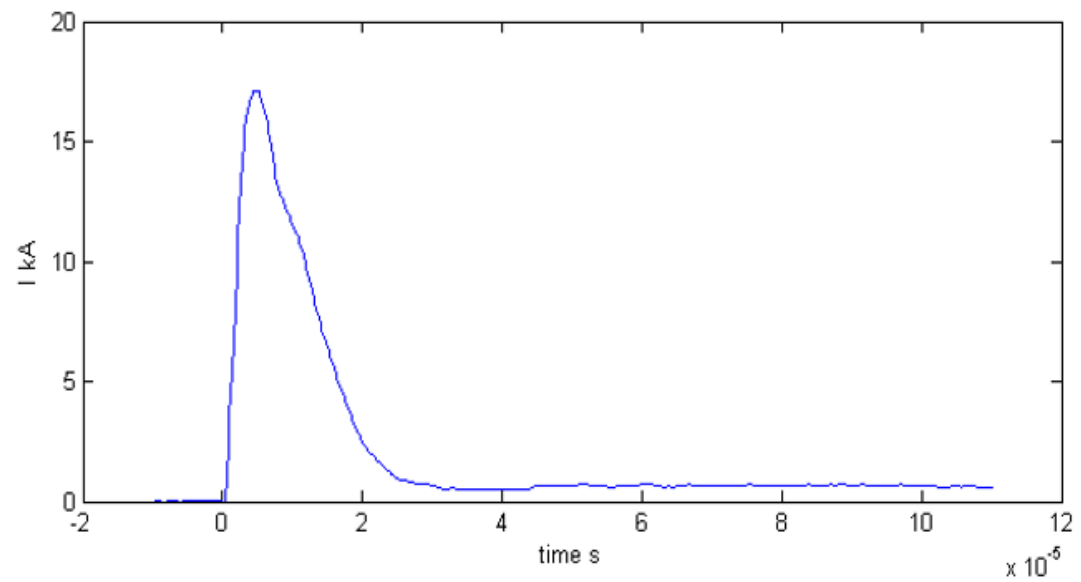

Fig. 7. The oscillogram of the current pulse according to the real (experimentally obtained) waveform of the lightning pulse 


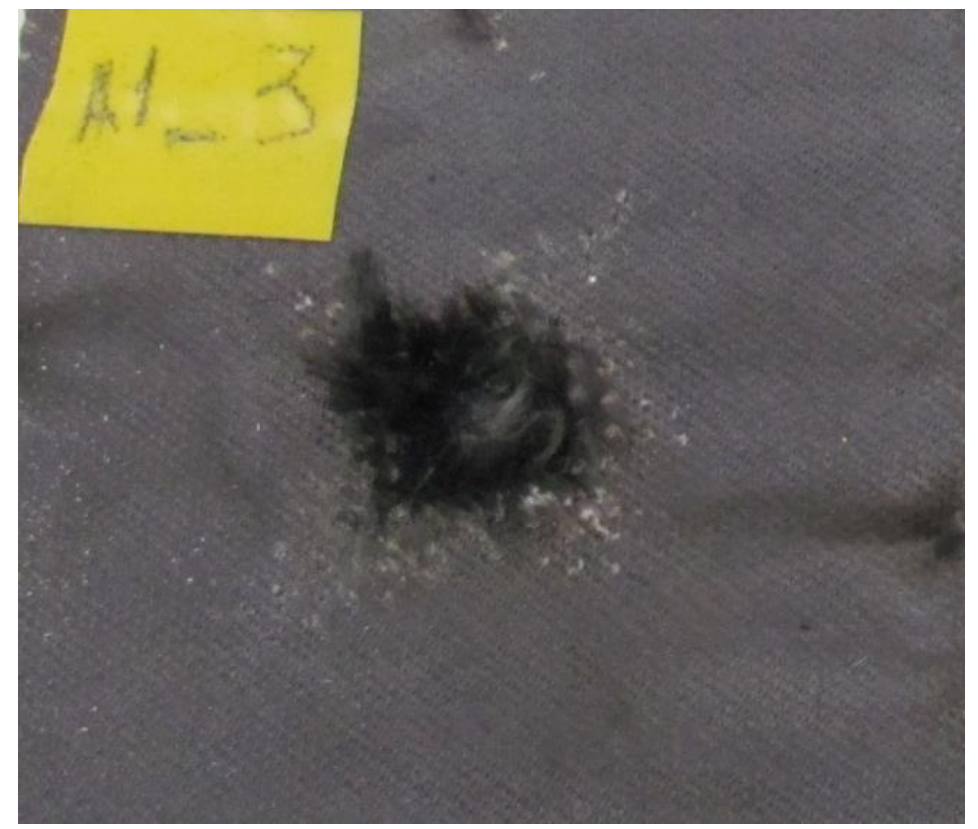

Fig. 8. Photos of the damage of the sample having been tested by the current pulse created by the «fast» stage and the «slow» stage of generator

As can be seen from the above photos, the level of destruction of the samples significantly increases in the presence of a long phase of the release of the current having the amplitude about $5 \%$ from the amplitude of the «standard» current pulse.

Fig. 9 shows the results of photo shooting the processes typical for the generator operating in the «fast» stage mode. Fig. 10 shows the results of photo shooting the processes corresponding to the impact on the composite materials samples in the mode of the combined action of the «fast» stage and the «slow» stage of the generator (photo shooting was carried out using neutral optical filter). 


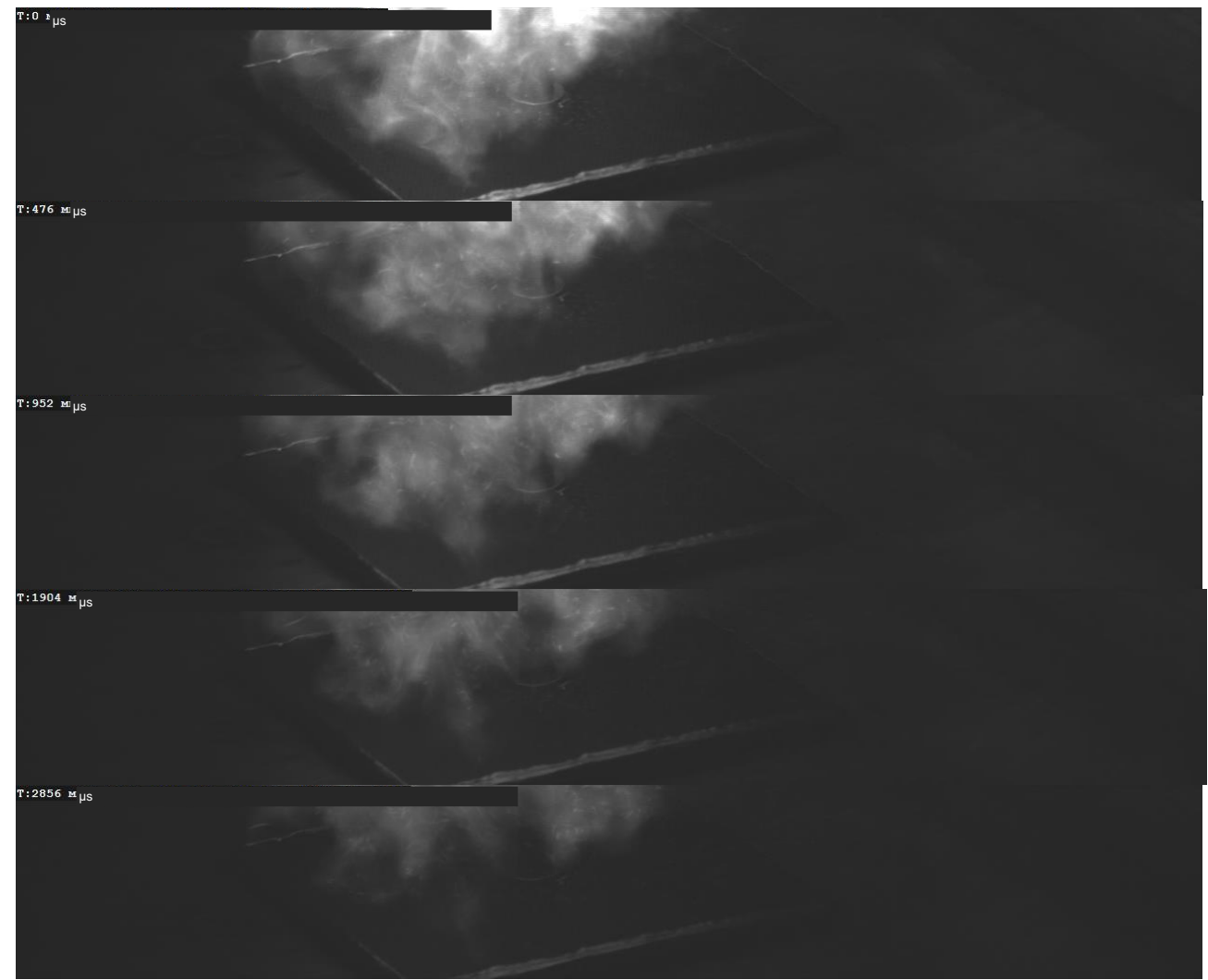

Fig. 9. A fragment of high-speed photography of the impact on the sample A1_1

The comparison of the obtained photos (Fig. 9 and Fig. 10) corresponding to the same time points makes it clear that the processes occurring in the samples of carbon fiber composite materials are significantly different.

The brightness of the discharge products is significantly higher during the action of the current pulse according to the real (experimentally obtained) waveform of the lightning current pulse (Fig. 10) than in the case of the impact of the «standard» lightning pulse (Fig. 9). Despite the low value of the current flowing via the sample at the «tail» of the pulse, the active breaking down of the materials doesn't cease after the end of the impact of the current pulse. 


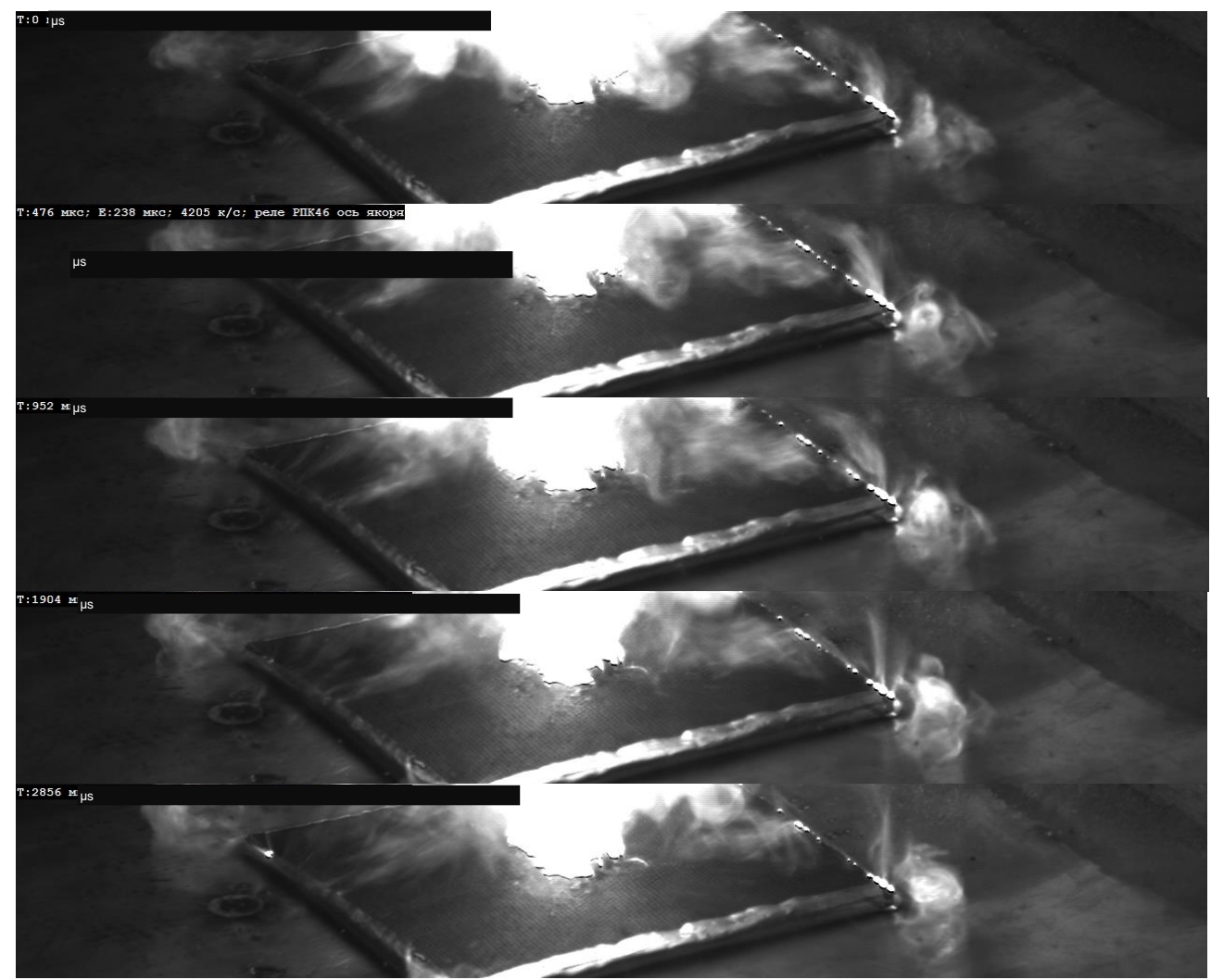

Fig. 10. A fragment of high-speed photography of the impact on the sample A1_3

\section{Conclusions}

The analysis of the dynamic images allows to make the following conclusions about the typical properties of breaking down the composite material:

1. Under the impact of the standard current pulse there is no significant material destruction. Actually it indicates that the whole charge is transferred by the displacement current and the ohmic heating of the fibers is negligible. Thus applying the standard pulse doesn't lead to significant destruction of the composite material.

2. Under the impact of the current pulse having a long «tail» time period (the current pulse close to the real one) there is an ignition of the carbon fiber composite material near the edges of the feeding electrode. The burning process doesn't end after the end of the current pulse. Furthermore there was a current propagation along the composite material fibers to the periphery of the sample reaching the edge of the sample and heating it. Thus the scale of destruction was in accordance with the entire size of the sample and was limited to its size, so in our opinion in the real-world situation the scale of destruction can increase considerably.

Work is performed under support of Federal target program "Research and development on priority directions of development of scientific-technological complex of Russia for 2014 - 2020 years". Agreement on the grant № 14.584.21.0019 from 30.11.2015 (Project No RFMEFI58416X0019), theme "The impact of experimentally obtained forms of lightning current pulse on the mechanical characteristics of composite structures". 


\section{References}

1. V. Goncharov, N. Korovkin, S. Krivosheev, News of the NTC of the Unified energy system, 1 (76) (2017)

2. A. Smorgonskiy, N. Korovkin, F. Rachidi, at al., Proc. of the Asia-Pacific Int. Symp. on $E M C$, 424-427 (2015)

3. A. Smorgonskiy, F. Rachidi, N. Korovkin, at al., IEEE Transactions on EMC, 59 (4), (2017)

4. K. Demirchyan, Y. Rakitskiy, P. Butyrin, at al., Izvestiya RAN. Energetika, 2 (1982)

5. M. Ianoz, N. Korovkin, Proc. of the IEEE 6th Int. Symp. on EMC and Electromagnetic Ecology, 1513046, 4-9 (2005)

6. A. Bondarenko, N. Korovkin, A. Lebedeva, T. Minevich, Transp. Research Procedia, 20, 68-73 (2017)

7. N. Belyaev, N. Korovkin, O. Frolov, V. Chudnyi, Russian Electrical Engineering, 84 (2), 74-80 (2013)

8. A. Smorgonskiy, F. Rachidi, at. al., Proc. of the Int. Symp. on Lightning Protection, 6088466 (2011)

9. N. Korovkin, S. Krivosheev, S. Shishigin, K. Netreba, Izvestiya RAN. Energetika, 6 (2013)

10. N. Korovkin, E. Selina, Proc. of the IEEE Int. Symp. on EMC, Part 1, 946-951 (1998)

11. N. Korovkin, T. Minevich, Radio electronics, 3 (2006)

12. N. Silin, N. Korovkin, T. Minevich, Proc. of the Int. Conf. on Industrial Engineering, App. and Manufacturing, 8076412 (2017)

13. N. Korovkin, S. Krivosheev, at al., Proc. of the 2018 IEEE Conf. of Russian Young Researchers in Electrical and Electronic Engineering, 686-691 (2018)

14. A. Adalev, N. Korovkin, M. Hayakawa, IEEE Transactions on Circuits and Systems I: Fundamental Theory and Applications, 55 (5), 1237-1247 (2008)

15. N. Korovkin, S. Shishigin, St. Petersburg State Polytechnical University Journal, 1 (166), 74-79 (2013)

16. N. Silin, N. Korovkin, St. Petersburg State Polytechnical University Journal, 63 (4), 186-192 (2008)

17. N. Korovkin, O. Frolov, D. Shishigin, S. Shishigin, Proc. of the IEEE Int. Symp. on EMC on EMC, 59 (4), (2017)

18. N. Korovkin, A. Lebedeva, T. Minevich, K. Netreba, S. Shishigin, St. Petersburg State Polytechnical University Journal, 4-1 (89), 202-206 (2009)

19. G. Evdokunin, N. Petrov, Proc. of the 2016 IEEE North West Russia Section Young Researchers in Electrical and Electronic Engineering Conf., 7448243, 553-556 (2016)

20. A. Smorgonskiy, F. Rachidi, M. Rubinstein, N. Korovkin, A. Vassilopoulos, Proc. of the IEEE Int. Symp. on EMC, 123882 (2016)

21. N. Korovkin, S. Krivosheev, V. Goncharov,. Proc. of the IEEE Russia Section Young Researchers in Electrical and Electronic Engineering Conf., 7910867 (2017) 